\title{
Do trecento ao cinquecento: história da língua italiana na perspectiva do contato e das políticas linguísticas
}

\author{
Tese de doutorado \\ Jefferson Evaristo do Nascimento Silva ${ }^{\mathrm{i}}$ \\ Orientadora: Prof. ${ }^{\text {a }}$ Dr. ${ }^{\text {a }}$ Annita Gullo ${ }^{\text {ii }}$ \\ Data de defesa: 26/08/2019
}

Palavras-chave: Língua italiana; História da língua italiana; Contato linguístico; Políticas linguísticas.

No dia 26/08/2019, defendemos a tese de doutorado na UFRJ, cujo tema era "Do trecento ao cinquecento: história da língua italiana na perspectiva do contato e das políticas linguísticas”. A pesquisa foi desenvolvida no Programa de Pós-graduação em Letras Neolatinas, tendo iniciado em 2016.

Nossa hipótese dizia respeito a uma inquietação, enquanto pesquisador e professor, em relação à área comumente denominada como italianística, especificamente em relação à história da língua italiana. Havia uma inquietação concernente ao modo como, em geral, os linguistas italianos tratam a história dessa língua, tendo eles uma perspectiva profundamente dialetológica e voltada para as mudanças internas da língua e das suas estruturas, privilegiando mudanças morfológicas, ortográficas, lexicais e/ou sintáticas, majoritariamente - com razão, admitimos - a partir do confronto com o latim. Assim, autores como Avolio (2017), Migliorini (2016), Cella (2015), Serianni (2015; 2011), De Mauro (2011), Trifone (2010), Marazzini (2012), Diaconescu (2008), Aierre (1997) e Lanuzza (1994) seriam importantes linguistas italianos, embora tratassem da história da língua italiana numa

\footnotetext{
${ }^{i}$ Doutor em Letras Neolatinas, opção língua Italiana, pela Universidade Federal do Rio de Janeiro (UFRJ) jeff.evaristo2@gmail.com | https://orcid.org/0000-0002-7561-5400

ii Programa de Pós-Graduação em Letras Neolatinas (UFRJ).
} 
perspectiva, digamos, estreita: interessariam a esses autores, de maneira geral, as mudanças estruturais da língua. Quando abordam outros fatores relevantes - como os que aqui discutimos -, eles o fazem como justificativa para as mudanças de que tratam logo depois.

Também os historiadores da língua italiana - Balbo (2011), Pizzoli (2011), Procacci (2009), Beales e Biagini (2005), Milza (2005), Sabbatucci e Vidotto (1994), por exemplo - trazem pouca contribuição a esse respeito. Em geral, suas análises tratam, no sentido disciplinar do termo, dos feitos "históricos" por que a Itália passou para ser o que é hoje. O argumento sobre a importância da língua é apagado, ainda que ele seja de importância fundamental, como vimos no desenvolvimento da investigação.

Esse contexto de aparente superficialidade do tratamento dos teóricos italianos levou-nos à hipótese que discutimos acerca dos eventos pré-unitários da língua italiana como verdadeiros eventos fundadores dessa língua. A ausência dessas pesquisas, também em âmbito brasileiro - como ficou demonstrado na introdução, quando falamos da pós-graduação brasileira e dos únicos dois programas de língua italiana -, motivounos à empresa. Nosso cenário de investigação, portanto, estava colocado e, igualmente, justificado, além de considerar ainda o caráter de originalidade desta pesquisa.

Metodologicamente, era preciso ainda estipular um recorte cronológico que desse sustento às investigações. Chegamos, então, ao período compreendido entre o trecento italiano e o início do cinquecento - com foco majoritário no quattrocento. Como argumentos relevantes do período, chegamos ao trabalho dos literatos e humanistas, da Igreja Católica e da imprensa, donde resultou nossa pergunta de pesquisa: qual a influência dos literatos italianos, da Igreja e da imprensa (séculos XIV a XVI) na unificação da língua italiana?

Para compreender a questão, estipulamos alguns conceitos iniciais daquilo que chamamos de "história pré-unitária da língua italiana", ocasião em que as contribuições de Janson (2015), Bagno (2011), Faraco (2006), Trudgill (2000) e Melo (1981) ajudaram-nos a compreender melhor a questão. A necessidade da pesquisa remeteu-nos ao período do Império Romano. Foi preciso retomar alguns princípios que estavam presentes, de maneira um tanto ou quanto difusa, no território da atual Itália. Uma breve observação acerca do Império Romano mostrou-nos como, naquela ocasião, um importante fator de unificação política, territorial e administrativa estava na língua 
latina. Além dos já citados linguistas italianos, ajudaram-nos as contribuições de Mendes e Silva (2014) e, principalmente, de Veyne (2009). Ali, expusemos os aspectos iniciais que permitiram ao território possuir aquilo que Avolio (2017) chama de riqueza linguística italiana: a sua profusão de diferentes línguas, motivadas pelos mais variados fatores de mudança sociolinguística.

\begin{abstract}
No nível linguístico, a consequência dos eventos históricos rapidamente referidos aqui é exemplificada no surgimento e no prosperar de uma "selva" de idiomas que são fortemente diferentes uns dos outros. (...) A variedade e a diferença dos dialetos é o resultado da diversidade das correntes inovadoras que investiram no latim nas diferentes regiões, diversidade possibilitada e garantida ao longo dos séculos pelos acontecimentos históricos descritos. ${ }^{1}$ (DE MAURO, 2011, p. 21)
\end{abstract}

A mesma noção de selva de dialetos será retomada em Trifone (2010), para quem, a considerar o número de línguas existentes na Itália, deveria ser escrita uma "história linguística da Itália desunida", privilegiando outras leituras do processo de consolidação do fiorentino. Sugerimos a empresa a outros pesquisadores.

Nossa discussão, na sequência, passou ao trecento italiano e ao movimento iniciado por Dante Alighieri para a escolha de um volgare ilustre. Volgare, em princípio, designaria qualquer língua vulgar, popular, em contraponto com a língua latina, profundamente normatizada, erudita e já experimentada nos séculos pelos grandes autores latinos. Volgare, entretanto, passará a designar especificamente uma dentre todas as línguas vulgares, a que mais prestígio teve e que se projetou de maneira contundente ao ponto de ser considerada língua oficial da Itália.

A Dante, seguiram-se outros autores de destaque no cenário italiano, como Boccaccio e Petrarca. Os três, cada qual a seu modo, modelaram a língua de Firenze para que pudesse ser uma língua literária. Porém, "a influência das obras em volgare de Dante, Petrarca e Boccaccio será decisiva para a língua italiana, mas não foi uma influência imediata ${ }^{2} "$ (CELLA, 2015, p. 43).

Inúmeros obstáculos colocavam-se entre a língua proposta por Dante e a sua aceitação por todos. Em uma Itália ainda dividida em reinos que, por vezes, confrontavam-se mutuamente, ter a língua de um potencial inimigo imposta como sendo sua não era uma realidade facilmente aceitável. Deveriam haver outros elementos que permitissem esse uso. 
Dessa forma, fatores culturais, políticos, intelectuais, econômicos, militares e administrativos foram se somando para que, gradualmente, o volgare oriundo de Firenze, na Toscana, pudesse ser aceito em outras regiões. Era um tempo de profundas mudanças no ordenamento da sociedade, com transformações históricas que são estudadas até hoje em todos os cantos do mundo. A bem da verdade, o exemplo italiano - e toda a história italiana desses séculos - é um patrimônio de toda a humanidade e encontrará eco em outros contextos.

Firenze, à época, era já um centro cosmopolita, para o qual acorriam multidões de comerciantes, por exemplo. A diversidade linguística da região era tamanha que era necessário haver uma língua na qual todos pudessem se comunicar. O latim, por sua vez, estava já em decadência (SERIANNI, 2015, p. 67), tendo sido suplantado através dos séculos pelos idiomas locais, resistindo, porém, nas trincheiras dos usos mais letrados e das situações mais formais. Paulatinamente, o comércio passa a adotar o volgare como língua de uso (DE MAURO, 2011, p. 24), ainda que Roma, por exemplo, fizesse-lhe uma exceção ${ }^{3}$.

Os três trecentistas eram lidos em maior número pelos reinos. Sua língua literária chegava aos recantos da península, sem que tivesse impacto real na fala dos homens desses lugares. Faltava ainda algum elemento de ligação entre os pontos, papel desenvolvido pela Igreja Católica (AQUINO, 2016; EVANGELISTI, 2015; DANIELROPS, 2014a; 1996; HERTLING, 1989). Seus pregadores e santos fizeram com que o fiorentino falado chegasse a locais que, sem a atuação da Igreja, demorariam ainda séculos para chegar; ou, possivelmente, nem chegariam, uma vez que não dá para dimensionar quais seriam os desdobramentos possíveis para a península italiana sem o fator de coesão que a língua possibilitou ao território.

Agostinho de Hipona, um dos teóricos discutidos em relação ao conceito de política, aponta ainda, em frase célebre, uma questão fundamental que os pregadores souberam considerar: melius est reprehendant nos grammatici quam non intelligant populi $^{4}$. A eles, mais valeria a repulsa dos gramáticos no uso do volgare se, com isso, as almas fossem atingidas.

Junto ao uso comercial, é de destaque o uso crescente pela administração pública, como nos exemplos dos príncipes e das cortes aos quais nos referimos. Prosseguia-se, com isso, aquilo que Cella (2015, p. 48) expunha sobre o toscano passar 
a ser aceito em todas as situações para as quais habitualmente apenas o latim era aceito. Em paralelo, os humanistas agiam indiretamente para a consolidação do volgare, dandolhe contornos normatizados e a padronização que faltava: é obra deles, por exemplo, a primeira gramática moderna escrita pelo movimento humanista, creditada a Leon Battista Alberti (MARAZZINI, 2012, p. 96-98). Completava-se com isso aquilo que seria, talvez, a contribuição mais importante dos humanistas: a aproximação com o latim, ação que permitiria ao volgare ser aceito mais facilmente em outras regiões por ser mais familiar aos outros ${ }^{5}$.

O cenário, todavia, estava em transição, assim como a sociedade. Entre Dante e Petrarca, por exemplo, há um abismo de diferenças. Onde um é latino, o outro é vulgar; onde um é religioso, o outro é antropocêntrico; onde um é feudal, o outro começa a ser moderno. Encarna-se nos dois uma transição de espírito que marcaria de forma indelével todo o cenário em que investigamos.

Marcou o período indelevelmente, também, a invenção da imprensa realizada na segunda metade do século XV e aqui discutida, também, a partir de Crupi (2012), Queiroz (2005), Arrigoni (2003), Burke (2002), Braida (2000), Bacelar (1999) e Tavani (1999). O potencial de publicação de obras, outrora dependentes dos monges copistas, ampliava-se exponencialmente a partir dos tipos móveis. Os livros, antes peças artesanais e com preço elevado, poderiam ser relativamente popularizados, num movimento que expandiria os limites de Firenze e cooperaria com o trabalho dos humanistas.

Esse é o caminho pelo qual a indústria do livro promoveu fortemente a aceitação de uma norma comum, tanto na gramática quanto no vocabulário. A geração dos últimos trinta anos do século $[\mathrm{XV}]$ não será suficiente, é claro, para produzir efeitos radicais; mas se considerarmos o desenvolvimento do italiano comum também nas duas gerações seguintes, até meados do século XVI, veremos que a imprensa trouxe uma contribuição decisiva para uma maior estabilidade e uniformidade da língua ${ }^{6}$. (MIGLIORINI, 2016, p. 230)

Foi o fator que colaborou, inclusive, com a atuação de Pietro Bembo. Era a época da toscanização das obras literárias, para que se adequassem ao fiorentino, ou mesmo da republicação de obras traduzidas em volgare. Milano, Brescia e Veneza são exemplos da questão, tanto quanto Ferrara e Napoli (MIGLIORINI, 2016, p. 227). Apenas como publicação ou republicação das obras dos três trecentistas maiores, 
Migliorini (2016, p. 229) cita as cidades de Veneza, Napoli, Roma, Foligno, Mantova, Iesi, Padova, Cavalca, Milano e Bologna, como sendo exemplos em um intervalo de menos de uma década.

Naturalmente, a imprensa não trouxe contribuições apenas para a Itália; nosso argumento concentra-se neste país porque nosso corpus é esse. Da mesma forma, a sua influência não está restrita ao plano linguístico, mas se estende a todos os âmbitos da vida humana, não apenas ao "mundo acadêmico".

\begin{abstract}
A ela [a imprensa] se deve uma marca indelével em todos os aspectos da cultura europeia, ou pelo menos, aceitar-se-á pacificamente que constituiu o instrumento de mudança que permitiu a emergência da ciência, religião, cultura, política e modos de pensar vulgarmente associados à cultura ocidental da era moderna (BACELAR, 1999, p. 1)
\end{abstract}

Em toda a nossa exposição, ainda, foi marcante uma aproximação com a Literatura ou com os exemplos literários. Brito (2018), Carpeaux (2012a; 2012b), Distante e Coelho (2008), Coelho (2005) e Arrigoni (2003) foram alguns dos que contribuíram para aproximar nossa discussão com a Literatura.

Por fim, haveria ainda duas dimensões a serem tratadas e que constituíram, de fato, nossa proposta como sendo ainda mais original: a aproximação que fizemos entre as políticas linguísticas e o contato linguístico, em diálogo com a história da língua. Em relação às políticas linguísticas - e à noção de política -, as obras de Bagno (2017), Rossi (2015), Gallo (2014), Guimarães (2012), Aulete (2011), Maquiavel (2011), Aranha (2009), Calvet (2007), Japiassú e Marcondes (2001) e Agostinho (1999) foram algumas das que nos permitiram traçar considerações acerca do assunto.

Em relação à noção de história da língua e contato linguístico, ressaltamos as contribuições de Berrutto (2018; 1995) Bagno (2017; 2011), Faraco (2016; 2006), Janson (2015), Guisan (2015; 2011), Basso e Gonçalves (2014), Britain (2013), Winford (2013), Muysken (2013), Hickey (2013a; 2013b), Trudgill (2013; 2000), Everett (2012), Couto (2009), Santipolo (2002), Mufwene (2001), Thomason (2001), Albanese e Albanese (1986) e Chambers e Trudgill (1980). A partir delas foi possível fundamentar um ponto da discussão que consideramos fundamental. Porém, seja dito, de qualquer modo, que toda a discussão perpassou a noção de contato linguístico, não estando ela restrita especificamente a um único capítulo ${ }^{7}$.

Nossa tese trouxe um ponto de vista no qual, de fato, as discussões e áreas de conhecimento viam-se interligadas, misturadas de tal modo que seria difícil separá-las. 
O exemplo italiano é um exemplo da história das mentalidades e da história das línguas. Com as devidas proporções, o que aconteceu em relação à língua italiana é o que aconteceu, também, com as outras línguas nacionais da Europa: a padronização e a eleição de uma língua única que seria tomada como nacional e que seria, posteriormente, envolvida por uma narrativa que lhe desse um status de perenidade em toda a história da nação. Se Leon Battista Alberti escrevia a primeira gramática humanista na Itália, Antonio de Nebrija o seguiria e escreveria a primeira gramática em língua castelhana em 1492 (MORA, 2012, p. 701), John Palsgrave escreveria sua L'esclarcissement de la langue françoise, em 1530, Fernão de Oliveira escreveria a sua Gramática da lingoagem portuguesa em 1536 (LINHARES e ALENCAR, 2015, p. 232). Linhares e Alencar indicam ainda gramáticas de autores nas atuais Polônia, Dinamarca, República Tcheca, Alemanha, Hungria, Holanda e Inglaterra. Todos os autores ou eram humanistas ou possuíam influência neles, demonstrando o alcance do movimento iniciado na Itália. No Brasil, Padre José de Anchieta faria a sua $A$ arte de Grammatica da Lingoa mais usada na costa do Brasil apenas em 1596, demonstrando ainda como o exemplo europeu seria replicado em outras terras.

Portanto, recorrente em outras línguas, nossa investigação aponta princípios que podem ser identificados em outros idiomas e que, efetivamente, fez parte de toda a formação das línguas europeias, como defendido por Guisan $(2015 ; 2011)$ ou autores como Everett (2012) e Anderson (2008).

Pode-se argumentar que a história de uma língua não é senão uma declinação particular da história geral, da mesma maneira que a história da arte ou das instituições sociais. De fato, como observamos nas páginas anteriores, há muitos temas pertencentes à história linguística externa que interpelam o historiador da língua. ${ }^{8}$ (SERIANNI, 2015, p. 111)

Embora nosso trabalho não seja o de um historiador - pelo menos não exatamente dentro daquilo que Marc Bloch (2002) chamava de ofício do historiador-, tangenciamos discussões históricas a todo momento. Nossa tentativa - que, no presente momento, julgamos poder dizê-la terminada -, no entanto, tencionou aproximar os estudos linguísticos da História ${ }^{9}$, sem que fosse um estudo eminentemente histórico. Traçamos uma linha que perpassou um mundo em transição, como na metáfora a que aludimos em Dante e Petrarca.

O acontecimento humano que constitui o objeto da História continua, de ano para ano, de geração em geração, de século em século: muito é o que muda, e muito o que permanece, sem nunca parar, sem nunca chegar um ano ou uma 
década que pode ser dito como o que termina um período para começar outro. Quaisquer que sejam os períodos em que dividamos o curso da história, sejam breves ou longos, sempre serão fases de transição, nas quais o novo é mesclado com o antigo. ${ }^{10}$ (HERTLING, 1989, p. 285)

Propusemo-nos a tentar organizar o quebra-cabeças ao qual, teoricamente, convenciona-se dar o nome de língua italiana. Ao buscar remontar suas peças, percebemos que seria necessário colhê-las nas mais diversas caixas. Seria possível dizer que fizemos um trabalho interdisciplinar, o que seria verdadeiro se se considerasse que a interdisciplinaridade que fizemos tivesse como eixo central a língua italiana.

Sabemos, porém, que muito foi ignorado nas poucas páginas que escrevemos. Há lacunas significativas em nossa proposta, o que, para nós, representa um ganho teórico: não esgotamos nossos argumentos, mas deixamo-los abertos para novas discussões. Necessárias que são, que elas venham.

\section{Referências}

ABBAGNANO, Nicola. Dicionário de Filosofia. São Paulo: Martins Fontes, 2007

AGOSTINHO, Santo. A cidade de Deus. Lisboa: Fundação Calouste Gulbenkian, 1999. Disponível em https://bit.ly/2xgpgMz. Acesso em 23 Mai. 2020.

AIERRE. Il dialetto: dignità di comunicazione, dignità sociale. Bari: AIERRE, 1997.

ALBANESE, Carolina M.; ALBANESE, Luciana. La questione della lingua italiana attraverso i secoli. Revista Letras - Curitiba, UFPR. 1986.

ALIGHIERI, Dante. De vulgari eloquentia. Torino: UTET, 1986.

ANDERSON, Benedict. Comunidades imaginadas. São Paulo: Companhia das Letras, 2008.

AQUINO, Felipe Rinaldo Queiroz de. História da Igreja - Idade Média. Lorena/SP: Cléofas, 2016.

ARANHA, Maria Lúcia de Arruda; MARTINS, Maria Helena Pires. Filosofando: introdução à filosofia. São Paulo: Editora Moderna, 2009.

ARRIGONI, Maria Teresa. Dante, Petrarca, Boccaccio e a tradução. Cadernos de Tradução (UFSC), Florianópolis, v. VIII, p. 29-39, 2003. 
AULETE, Caldas. Novíssimo Aulete - Dicionário Contemporâneo da Língua Portuguesa. Rio de Janeiro: Lexikon, 2011.

AVOLIO, Francesco. Lingue e dialetti d'Italia. Roma: Carocci Editore, 2017.

BACELAR, J. Apontamentos sobre a história e desenvolvimento da impressão. Lisboa: Biblioteca On-line de Ciências da Comunicação, 1999. Disponível em http://www.bocc.uff.br/pag/bacelar_apontamentos.pdf. Acesso em 10 mai. 2020.

BAGNO, Marcos de A. Dicionário Crítico de Sociolinguística. São Paulo: Parábola, 2017

BAGNO, Marcos de A. O que é uma língua? Imaginário, Ciência e Hipóstase. In: LAGARES, X.; BAGNO, M. (orgs.). Políticas da norma e conflitos linguísticos. São Paulo: Parábola, 2011.

BALBO, Cesare. Storia d'Italia e altri scritti. Torino: UTET Libreria, 2011.

BALBONI, P. E. Le sfide di Babele. Insegnare le lingue nelle società complesse. UTET Libreria. Itália, Torino: 2002.

BASSO, Renato Miguel; GONÇALVES, Rodrigo Tadeu. História concisa da língua portuguesa. Petrópolis: Editora Vozes, 2014.

BEALES, Derek; BIAGINI, Eugenio F. Il Risorgimento e L'Unificazione dell'Italia. Bologna: Il Mulino, 2005.

BERRUTTO, Gaetano. 2018. Contatto Linguistico. Enciclopedia Treccani dell'Italiano - http://migre.me/w2Jq3 - Acesso em 02/05/2020 às 11h39min.

BERRUTTO, Gaetano. Sociolinguistica dell'italiano contemporaneo. Roma: La Nuova Italia Editrice, 1995.

BÍBLIA. Português. A Bíblia de Jerusalém. Nova edição revista e ampliada. São Paulo: Paulus, 2013.

BILIA, Marilisa Bertechini. Análise lexical das interferências da língua portuguesa na língua italiana falada por italianos de nível universitário residentes na cidade de São Paulo. 01/11/1998 184 f. Mestrado em Letras (Língua e Literatura Italiana) Instituição de Ensino: Universidade de São Paulo, São Paulo Biblioteca Depositária: da Faculdade de Filosofia, Letras e Ciências Humanas.

BLOCH, Marc. Apologia da história: ou o ofício do historiador. Rio de Janeiro: Jorge Zahar Editor, 2002.

BORTONI-RICARDO, Stella Maris. O professor pesquisador: introdução à pesquisa qualitativa. São Paulo: Parábola Editorial, 2008. 
BRAIDA, Lodovico. Stampa e cultura in Europa tra XV e XVI secolo. Bari: Laterza, 2000.

BRITAIN, David. Contact and Dialectology. In: HICKEY, Raymond. The Handbook of language contact. New Jersey: Wiley-Blackwell, 2013.

BRITO, Emanuel França de. Da prosa latina ao volgare: o nascimento de uma identidade linguística para além a poesia. Revista de Italianística da USP, v. 37, p. 8794, 2018. Disponível em

www.revistas.usp.br/italianistica/article/download/155653/151352/. Acesso em 13/05/2020.

BRITTO, Fabiano de L. Identidade cultural e formação individual: a Alemanha do século XIX e a fundação da pedagogia moderna. Educ. Soc., Campinas, v. 33, n. 118, p. 217-233, jan.-mar. 2012.

BURKE, Peter. Problemas causados por Gutenberg: a explosão da informação nos primórdios da Europa moderna. Revista Estudos Avançados, vol.16 no.44 São Paulo, 2002.

CALVET, Louis-Jean. As políticas linguísticas. São Paulo: Parábola/Ipol, 2007.

CARNEIRO, M. T. (Org.). Pistas e travessias. 1 $^{\text {a }}$ ed. Rio de Janeiro: Editora da Universidade do Estado do Rio de Janeiro, 1999.

CARPEAUX, Otto Maria. A Idade Média por Carpeaux. Rio de Janeiro: Leya, 2012 ${ }^{\mathrm{a}}$.

CARPEAUX, Otto Maria. O Renascimento e a Reforma por Carpeaux. Rio de Janeiro: Leya, $2012 b$.

CASINI, M. C.; ROMANELLI, Sergio. Italianistica in Brasile: ricerca di prospettive e prospettive di ricerca. In.It, v. 27, p. 16-21, 2011.

CASSELL, C., \& SYMON, G. Qualitative Methods in Organizational Research. Sage Publications: London, 1994.

CASTAGNOLA, Luigi. Primeiro milênio da língua italiana. Revista Letras, v. 12 (1961). Disponível em http://revistas.ufpr.br/letras/article/view/19890. Acesso em 14 mai. 2020.

CELLA, Roberto. Storia dell'italiano. Il Mulino: Bologna/Italia, 2015.

CHAMBERS J. K.; TRUDGILL, P. Dialectology. New York: Cambridge University Press, 1980.

CHARAUDEAU, Patrick; MAINGUENEAU, Dominique. Dicionário de Análise do discurso. São Paulo: Contexto, 2016. 
CHIAVEGATTO, V. (Org.). Pistas e Travessias II. Rio de Janeiro: EDUERJ, 2002.

COELHO, Flora Simonetti. Antologia della letteratura italiana - Dalle origini al quattrocento. Rio de Janeiro: H.P. Comunicação editorial, 2005.

CÔELHO, Ildeu Moreira. A gênese da docência universitária. Linhas Críticas, Brasília, v. 14, n. 26, p. 5-24, jan./jun. 2008.

COUTO, Hildo Honório do. Linguística, Ecologia e Ecolinguística: Contato de Línguas. São Paulo: Contexto, 2009.

COUTO, Leticia R.; PEREIRA, Telma C. A.; SILVA, Maria I. A. da. Fronteiras territoriais e fronteiras linguísticas: análise ecolinguística em regiões de contato Brasil/Venezuela e Brasil/França: as "redes sociais" e a "arena de traços". In: Mônica Maria Guimarães Savedra; Marco Antonio Martins; Dermeval da Hora. (Org.). Identidade Social e contato linguístico no português brasileiro. Rio de Janeiro: FAPERJ; EDUERJ, 2015.

CRIPPA, Giulia. A vida econômica e social na alta Idade Média italiana e a constituição do gênero representativo dos ciclos dos meses nos reinos longobardos e francos.

História Revista - Revista da Faculdade de História e do Programa de Pós-Graduação em História da Universidade Federal de Goiás, v.11, nº 1. 2006.

CRUPI, Gianfranco. Gli incunaboli italiani in lingua volgare: preliminari di una ricerca. Roma: Sapienza Università Editrice, 2012.

DE MAURO, Tullio. Storia linguistica dell'Italia unita. Bari: Laterza, 2011.

DANIEL-ROPS. A Igreja das catedrais e das cruzadas. São Paulo: Quadrante, 2014a.

DANIEL-ROPS. A Igreja dos apóstolos e dos mártires. São Paulo: Quadrante, 2014b.

DANIEL-ROPS. A Igreja da Renascença e da Reforma (I). São Paulo: Quadrante, 1996.

DIACONESCU, Roxana. L'italiano e i dialetti: alcune interferenze linguistiche.

Craiova: Libreria Universitaria, 2008.

DISTANTE, Carmelo; COELHO, Flora Simonetti. Antologia della letteratura italiana. São Paulo: Editora Hucitec, 2008.

ECO, Umberto. Em busca da língua perfeita. Bauru: EDUSC, 2001.

ENDRUSCHAT, Annette; SCHMIDT-RADEFELDT, Jürgen. Introdução básica à linguística do português. Lisboa: Edições Colibri, 2015. 
EVANGELISTI, Paolo. "Dunque non sognate, fate fatti non solo parole": Bernardino de Siena e a proposta franciscana de uma religião civil. Revista Varia História, Belo Horizonte, v. 31, n. 55, p. 81-125, abr. 2015.

EVERETT. Daniel. Language: the cultural tool. New York: Pantheon, 2012.

FARACO, C. A. História sociopolítica da língua portuguesa. São Paulo: Parábola Editorial, 2016.

FARACO, C. A. Linguagem \& Diálogo. As ideias linguísticas do Círculo de Bakhtin. São Paulo: Parábola Editorial, 2009.

FARACO, C. A. Linguística Histórica: uma introdução ao estudo da História das línguas. São Paulo: Parábola Editorial, 2006.

FONSECA, Maria C. B. A Arte de Grammatica da Lingoa mais usada na costa do Brasil, de José de Anchieta, no quadro da gramaticalização de vernáculos europeus. Trabalho apresentado em Estudos em Homenagem ao Professor Doutor, In: Estudos em Homenagem ao Professor Doutor Mário Vilela. Porto, 2005. Disponível em https://ler.letras.up.pt/uploads/ficheiros/4555.pdf - acesso em 02/05/2020 às 23h15.

FORTES, Fabio; PRATA, Patricia. O Latim hoje - reflexões sobre cultura clássica e ensino. São Paulo: Mercado de Letras, 2015.

FREDDI, G. Glottodidattica:Fondamenti, metodi e tecniche. Torino: UTET Libreri, 2006.

GALLO, Silvio. Filosofia: experiência do pensamento. São Paulo: Scipione, 2014.

GOMES, Andrea C. de S.; et ali. A história da língua italiana e sua escolha dentre tantas possibilidades. Revista Linguasagem, v. 22, n. 1, 2015.

GONÇALVES, Patrícia A. De babel a pandora: crise, cultura e identidade no multilinguismo italiano. In: XÓAN Lagares \& MARCOS Bagno. (Org.). Políticas da Norma e Conflitos Linguísticos. São Paulo: Parábola Editorial, 2011.

GUIMARÃES, M. O pensamento político de Dante Alighieri à luz da Filosofia Escolástica. 165f. Tese (Doutorado em educação) - Universidade Estadual de Maringá, 2012.

GUISAN, P. F. G. O paradigma da língua na formação do nacionalismo brasileiro. In: Mônica Maria Guimarães Savedra; Marco Antonio Martins; Dermeval da Hora. (Org.). Identidade Social e contato linguístico no português brasileiro. Rio de Janeiro: FAPERJ; EDUERJ, 2015.

GUISAN, P. F. G. A criação de uma norma-padrão em francês: entre planejamento político e mito. In: LAGARES, X. C.; BAGNO, M. (orgs.). 2011. Políticas da norma e conflitos linguísticos. São Paulo: Parábola, 2011. 
HERTLING, Ludwig. Historia de la Iglesia. Barcelona: Editorial Herder, 1989.

HICKEY, Raymond. Contact and language swift. In: HICKEY, Raymond. The Handbook of language contact. New Jersey/USA: Wiley-Blackwell, 2013a.

HICKEY, Raymond. The Handbook of language contact. New Jersey: WileyBlackwell, 2013b.

ILARI, Rodolfo. Linguística Românica. São Paulo: Contexto, 2018.

JANSON, Tore. A história das línguas: uma introdução. São Paulo: Parábola Editorial, 2015.

JAPIASSÚ, Hilton; MARCONDES, Danilo. Dicionário básico de Filosofia. Rio de Janeiro: Jorge Zahar Editor, 2001.

LAGARES, X. C. Continuidades e rupturas linguísticas na Península Ibérica. Revista da ABRALIN, v. Espec., p. 123-151, 2011.

LAGARES, X. C. Sobre a noção de galego-português. Cadernos de Letras da UFF, v. 35, p. 61-82, 2008.

LAGARES, X. C.; BAGNO, M. (orgs.). Políticas da norma e conflitos linguísticos. São Paulo: Parábola, 2011.

LANUZZA, Stefano. Storia della lingua italiana. Roma: Tascabili Economici Newton, 1994.

LE GOFF, JACQUES. Para Um Novo Conceito de Idade Média. Lisboa: Editorial Estampa, 1980

LIMA, Ivana Stolze; CARMO, Laura do. História Social da Língua Nacional: diáspora africana. Rio de Janeiro: Nau Editora/FAPERJ, 2014.

LIMA, Ivana Stolze; CARMO, Laura do. História Social da Língua Nacional: diáspora africana. Rio de Janeiro: Edições Casa de Rui Barbosa, 2008.

LORENZETTI, Luca. Lessico. Enciclopedia Treccani dell'Italiano. Disponível em: https://www.treccani.it/enciclopedia/elenco-opere/Enciclopedia_dell\%27Italiano. Acesso em 02 Nov. 2018.

MAQUIAVEL, Nicolau. O Príncipe. São Paulo: Hunter Books, 2011.

MARAZZINI, Claudio. La lingua italiana - profilo storico. Bologna: Il Mulino, 2012.

MARAZZINI, Claudio. Breve Storia Della Lingua Italiana. Bologna: Il Mulino editrice, 2004. 
MARCONI, Marina de Andrade; LAKATOS, Eva Maria. Fundamentos de metodologia científica. São Paulo: Atlas, 2010.

MATOS, Francisco Gomes de. Dicionário de linguagem e lingüística. DELTA, São Paulo, v. 21, n. 1, p. 161-163, June 2005.

MATTHEWS, P. H. Oxford Concise Dictionary of Linguistics. New York: Oxford, 2014.

MELO, Gladstone Chaves de. Iniciação à Filologia e à Linguística Portuguesa. $6^{\mathrm{a}} \mathrm{ed}$. Rio de Janeiro: Ao Livro Técnico, 1981.

MENDES, Norma Musco; SILVA, Gilvan Ventura da. Repensando o Império Romano: Perspectiva Socioeconômica, Política e Cultural. Espírito Santo: EDUFES, 2014.

MIGLIORINI, Bruno. Storia della lingua italiana. Milano/Italia: Tascabili, 2016.

MILZA, Pierre. Storia d'Italia: dalla preistoria ai nostri giorni. Milano: Editrice Corbaccio, 2005.

MINAYO, Maria C. de S; et al. Pesquisa social: teoria método e criatividade. Petrópilis/RJ, Vozes, 1994.

MORA, Maria José Rodrigo. Grammatichetta y Gramática: reflexión metalingüística en Alberti y en Nebrija. In: Metalinguaggi e metatesti. Lingua, letteratura e traduzione, XXIV Congresso AISPI (Padova, 23-26 maggio 2007), a cura di A. Cassol, A. Guarino, G. Mapelli, F. Matte Bon, P. Taravacci, Roma, AISPI Edizioni, 2012, pp. 697-707. Disponível em https://cvc.cervantes.es/literatura/aispi/pdf/23/23_697.pdf. Acesso em: 02 jul. 2019.

MUFWENE, Salikoko. The Ecology of language evolution. Cambridge: Cambridge University Press, 2001.

MUSSALIM, Fernanda; BENTES, Anna Christina (Org.). Introdução à linguística: domínios e fronteiras - volume 3. São Paulo: Cortez Editora, 2016.

MUSSALIM, Fernanda; BENTES, Anna Christina (Org.). Introdução à linguística: domínios e fronteiras - volume 2. São Paulo: Cortez Editora, 2012a.

MUSSALIM, Fernanda; BENTES, Anna Christina (Org.). Introdução à linguística: domínios e fronteiras - volume 1. São Paulo: Cortez Editora, 2012b.

MUYSKEN, Pieter. Scenarios for language contact. In: HICKEY, Raymond. The Handbook of language contact. New Jersey/USA: Wiley-Blackwell, 2013.

OLIVEIRA, Gilvan Muller de. Prefácio. In: CALVET, Louis-Jean. As Políticas Linguísticas. São Paulo: Parábola, 2007. 
PADRES APOSTÓLICOS. Clemente Romano, Inácio de Antioquia, Policarpo de Esmirna, O pastor de Hermas, Carta de Barnabé, Pápias, Didaqué. Coleção Patrística, Volume 1. São Paulo: Paulus, 1997

PAVAN, E. La cultura e la civiltà italiane e il loro insegnamento in una prospettiva interculturale. In: DOLCI, Roberto; CELENTIN, Paola. La formazione di base del docente di italiano per stranieri. Roma: Bonacci editore, 2000.

PIZZOLI, Lucilla. La lingua italiana negli anni dell'Unità d'Italia. Milano: Silvana Editoriali, 2011.

PROCACCI, Giuliano. Storia degli italiani. Volume secondo. Bari: Laterza, 2009.

QUEIROZ, Rita de C. R. A informação escrita: do manuscrito ao texto virtual. In: VI CINFORM - Encontro Nacional de Ciência da Informação, 2005, Salvador. Anais eletrônicos. Disponível em http://www.ufrgs.br/limc/escritacoletiva/pdf/a_info_escrita.pdf. Acesso em 11 abr. 2020.

REVISTA de Italianística da ABPI. v.1, n.1. Curitiba: Unigraf/UFPR, 2009.

REVISTA de Italianística da ABPI. v.2, n.1. Curitiba: Unigraf/UFPR, 2009.

ROSSI, Miguel Ángel. Palavra e Política em Aristóteles: uma discussão com Platão e os sofistas. Prometeus: Revista do Mestrado em Filosofia da UFS, v. 8, ano 8, n 17. 2015.

SABBATUCCI, Giovanni; VIDOTTO, Vittorio. Storia d'Italia: le premesse dell'Unità. Roma: Laterza, 1994.

SANTADE, Maria S. B. a metodologia de pesquisa: instrumentais e modos de abordagem. In: SIMÕES, Darcilia M. P.; GARCÍA, Flavio. A pesquisa científica como linguagem e práxis. Rio de Janeiro: Dialogarts, 2014.

SANTIPOLO, Matteo. Dalla sociolinguistica alla glottodidattica. Torino: Utet, 2002.

SERIANNI, Luca. Prima lezione di storia della lingua italiana. Roma: Laterza, 2015.

SILVA, Elias Ribeiro da. A pesquisa em Política Linguística: histórico, desenvolvimento e pressupostos epistemológicos. Trabalhos em Linguística Aplicada (UNICAMP), v. 52.2, p. 289-320, 2013.

SILVA, Renato Caixeta da. Estudos recentes em linguística aplicada no Brasil a respeito de livros didáticos de língua estrangeira. Revista Brasileira de Linguística Aplicada (RBLA). vol.10 No.1 Belo Horizonte, 2010.

SILVA, J. E. N.; GULLO, A.; GENOVA, L. de. La realtà linguistica dell'Italia nei libri didattici di italiano per stranieri: tra silenziamenti e omogeneità, la prevalenza 
dell'italiano standard. In: Jefferson Evaristo do Nascimento Silva et al. (Org.). Línguas e Culturas: Contatos, Conflitos, Nomadismos. 1ed.Rio de Janeiro: Faculdade de Letras/UFRJ, 2018, v. 1, p. 51-68.

TAVANI, Giuseppe. O texto medieval e as suas "misérias e desventuras". In: MALEVAL, Maria do A. T. Atas do III Encontro Internacional de Estudos Medievais. UERJ: Rio de Janeiro, 1999.

THOMASON, Sara Grey. Language Contact. Edinburgh: University Press, 2001.

TRIFONE, Pietro. Storia linguistica dell'Italia disunita. Bologna: Il Mulino, 2010.

TRIFONE, Pietro. Lingua e identità: una storia sociale dell'italiano. Roma: Carocci editore, 2006.

TRUDGILL, Peter. Contact and sociolinguistic typology. In: HICKEY, Raymond. The Handbook of language contact. New Jersey/USA: Wiley-Blackwell, 2013.

TRUDGILL, Peter. Sociolinguistics: An Introduction to Language and Society. London: Penguin Books, 2000.

VALVERDE, Antonio José Romera. Maquiavel e a origem política dos conceitos políticos Modernos. Aurora: revista de arte, mídia e política, São Paulo, v.6, n.18, p. 8589, out.2013-jan.2014.

VEYNE, Paul. O império greco-romano. Rio de Janeiro: Elsevier, 2009.

WINFORD, Donald. Contact and borrowing. In: HICKEY, Raymond. The Handbook of language contact. New Jersey/USA: Wiley-Blackwell, 2013.

Recebido em: 26/05/2020

Aceito em: 18/06/2020

\footnotetext{
1 "Sul piano linguistico, la conseguenza delle vicende storiche qui rapidamente richiamate è ravvisabile nel sorgere e nel prosperare secolare d'una "selva" di idiomi fortemente diversi gli uni dagli altri. (...) La varietà e difformità dei dialetti è il risultato della diversità delle correnti innovative che hanno investito il latino nelle diverse regioni, diversità resa possibile e garantita attraverso i secoli dalle vicende storiche prima descritte." (tradução nossa).

2 "L'influenza delle opere volgari di Dante, Petrarca e Boccaccio sarà decisiva per la lingua italiana, ma non fu immediata." (tradução nossa).

${ }^{3}$ Justamente por ser a sede da cristandade, que tinha o latim como língua sagrada, Roma resistia mais à influência do fiorentino. Se Piemonte resistia por suas características geográficas, Roma resistia por suas características religiosas. Isso não impedia, não obstante, o uso do volgare pelos religiosos no extramuros de Roma, como vimos.
} 
4 “É melhor sermos repreendidos pelos gramáticos do que não sermos entendidos pelo povo" (tradução nossa).

${ }^{5}$ Marazzini (2012, p. 98-99), por exemplo, defende ainda que tenha existido um volgare humanista, construção teórica do movimento e que teria se distanciado do modelo de Dante. A defesa, entretanto, carece de argumentos mais sólidos: se o volgare é humanista porque foi modificado por estes, deveria ser petrarquista e boccacciano pelos mesmos motivos; deveria, ainda, ser também eclesiástico ou "imprensístico". O argumento de Marazzini não é compartilhado por outros linguistas italianos, o que não deixa de ser outro indício de que sua hipótese não teria comprovação empírico-conceitual.

6 "Questa è la via per cui l'industria del libro promosse fortemente l'accettazione di una norma comune, sia nella grammatica che nel lessico. Non basterà, naturalmente, la generazione dell'ultimo trentennio del secolo [XV]a produrre effetti radicali; ma se prendiamo in considerazione lo svolgimento dell'italiano comune anche nelle due generazioni seguenti, fin verso la metà del secolo XVI, vedremo che la stampa ha portato un contributo decisivo a una maggiore stabilità e uniformità della lingua" (tradução nossa).

${ }^{7}$ Da mesma fora que praticamente em toda a tese a contribuição dos linguistas italianos era retomada.

8 "Si può sostenere che la storia di una lingua altro non sia che una particolare declinazione della storia generale, alla stregua della storia dell'arte o delle istituzioni sociali. In effetti, come abbiamo osservato nelle pagine precedenti, sono molti i temi appartenenti alla storia linguistica esterna che interpellano lo storico della lingua." (tradução nossa).

${ }^{9}$ Do mesmo modo como, por exemplo, da Filologia, argumento que circundou nossa discussão, quer de maneira direta, quer de maneira indireta.

10 "El acontecer humano que constituye el objeto de la Historia, prosigue incessantemente su curso, de año en año, de genereción en genereción, de siglo en siglo: mucho es lo que cambia, y mucho lo que permanece, sin que jamás ocurra una detención, sin que jamás venga un año o un decenio del que pueda decirse que en él termina un periodo y impieza uotro nuevo. Cualquiera que sean los periodos en que dividamos el decurso de la historia, sean breves o largos, se tratará siempre de fases de transición, en las que lo nuevo se mezcla con lo viejo" (tradução nossa). 